\title{
Pt Nanocluster Co-Catalysts for Photocatalytic Water Splitting
}

\author{
Cameron J. Shearer ${ }^{1, *}$, Jason F. Alvino ${ }^{1}\left(\mathbb{D}\right.$, Munkhbayar Batmunkh ${ }^{2}$ and Gregory F. Metha ${ }^{1, *}$ \\ 1 Department of Chemistry, The University of Adelaide, Adelaide 5005, Australia; \\ jason.alvino@adelaide.edu.au \\ 2 Australian Institute for Bioengineering and Nanotechnology, The University of Queensland, \\ St Lucia, Brisbane 4072, Australia; m.batmunkh@uq.edu.au \\ * Correspondence: cameron.shearer@adelaide.edu.au (C.J.S.); greg.metha@adelaide.edu.au (G.F.M.); \\ Tel.: +61-8-8313-4332 (C.J.S.)
}

Received: 18 October 2018; Accepted: 19 November 2018; Published: 22 November 2018

\begin{abstract}
Degussa P25 is a benchmark form of $\mathrm{TiO}_{2}$ used worldwide in photocatalysis studies. Currently, no such benchmark exists for co-catalysts, which are essential for many photocatalytic reactions. Here, we present the preparation of Pt nanocluster co-catalysts on $\mathrm{TiO}_{2}$ using an unmodified commercial source and equipment that is commonly available. Transmission electron microscopy reveals that the procedure produces $\mathrm{TiO}_{2}$ decorated with $\mathrm{Pt}$ atoms and nanoclusters (1-5 atoms). Optical reflectance and X-ray diffraction measurements show that the procedure does not affect the $\mathrm{TiO}_{2}$ polymorph or ultraviolet-visible (UV-Vis) absorbance. Gas phase photocatalytic splitting of heavy water $\left(\mathrm{D}_{2} \mathrm{O}\right)$ shows that the Pt nanocluster-decorated $\mathrm{TiO}_{2}$ outperforms Pt nanoparticle (produced by photodeposition) decorated $\mathrm{TiO}_{2}$ in $\mathrm{D}_{2}$ production. Pt nanoclusters, produced directly from a commercial source, with high co-catalyst activity, are prime candidates to be used in benchmark photocatalytic reactions.
\end{abstract}

Keywords: photocatalysis; co-catalysts; water splitting; hydrogen evolution; metallic cluster

\section{Introduction}

The Paris agreement of 2017 set a long term goal to limit global temperature rise to below $2{ }^{\circ} \mathrm{C}$ (above pre-industrial average) and to achieve this has set an aim to reduce greenhouse emissions as soon as possible (https://unfccc.int/). Energy production and transport are major contributors to greenhouse emissions, particularly in the form of $\mathrm{CO}_{2}$ from the combustion of fossil fuels. To reduce greenhouse gas emissions and achieve the goals of the Paris agreement, alternative fuel sources are required.

Hydrogen is a portable, renewable and non-polluting fuel source. The challenge holding back the wide scale use of hydrogen as a fuel source is the difficulty in its production from water splitting (Equation (1)). Electrolysis is the current commercial method to produce hydrogen from water, with typical power conversion efficiency of $65-75 \%$ [1]. Hydrogen produced from electrolysis is only non-polluting and renewable if the energy is derived from renewable sources (photovoltaics, wind, etc.) [2]. These processes themselves are also limited in efficiency and large infrastructure cost (both economic and environmental). An alternative approach to produce hydrogen in a renewable manner is via photocatalytic water splitting.

$$
\begin{gathered}
\mathrm{H}_{2} \mathrm{O} \rightleftharpoons \mathrm{H}_{2}+\frac{1}{2} \mathrm{O}_{2} \quad E_{o x}^{o}=-1.23 V, \Delta G=237 \mathrm{~kJ} \cdot \mathrm{mol}^{-1} \\
\mathrm{H}_{2} \mathrm{O} \rightleftharpoons \frac{1}{2} \mathrm{O}_{2}+2 \mathrm{H}^{+}+2 \mathrm{e}^{-}
\end{gathered}
$$




$$
2 \mathrm{H}^{+}+2 \mathrm{e}^{-} \rightleftharpoons \mathrm{H}_{2}
$$

Photocatalysis is a light-assisted catalysis where reactive intermediates are formed on the surface upon photoillumination. Some semiconductors (e.g., $\mathrm{TiO}_{2}, \mathrm{SrTiO}_{3}, \mathrm{BiVO}_{4}$, etc.) can act as a photocatalyst due to their intrinsic electronic structure composed of a filled valence (VB) and an empty conduction band (CB) $[3,4]$. When the semiconductor is illuminated by light with energy greater than its band gap $\left(h v \geq E_{g}\right)$, the VB electrons can be excited to the $C B$, leaving a positively charged hole in the VB. The photogenerated electrons and holes can drive reduction/oxidation reactions on the particle surface (Figure 1).

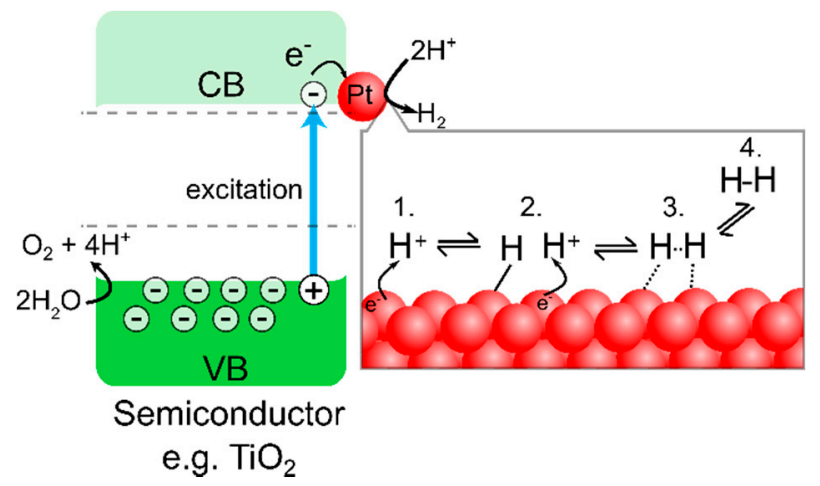

Figure 1. Schematic highlighting the process of water splitting via photocatalysis and the importance of the co-catalyst for the hydrogen evolution reaction (HER). HER follows: (1) Electron transfer from co-catalyst to $\mathrm{H}^{+}$. (2) $\mathrm{H}$ adsorption and electron transfer to second $\mathrm{H}^{+}$. (3) Electron transfer between neighbouring adsorbed hydrogen atoms to form chemical bond. (4) Desorption and release of $\mathrm{H}_{2}$.

To assist in driving the 2 electron transfer $\mathrm{H}_{2}$ evolution reaction (HER, Equation (3)), a co-catalyst is typically used. The role of the co-catalyst is to adsorb $\mathrm{H}^{+}$cations and facilitate electron transfer from the semiconductor interface to $\mathrm{H}^{+}$and may occur through either the Volmer-Heyrovsky or the Volmer-Tafel mechanism (Figure 1) [5-7]. This forward reaction is in competition with the backward reaction of electron-hole recombination. Theoretical and experimental investigations have concluded that the most active elements for the hydrogen evolution reaction are noble metals $(\mathrm{Pt}, \mathrm{Pd}, \mathrm{Rh})[6]$. In fact, Pt is clearly the most commonly used HER co-catalyst in the field [2,3].

Noble metals are rare and, therefore, expensive. Technoeconomic assessments of hydrogen production from photocatalytic water splitting typically show that the major factors in reducing the cost are solar-to-hydrogen (STH) efficiency and production cost $[8,9]$. Research in the field to reduce cost have looked at alternative co-catalysts such as sulphides and phosphides, which have shown production rates comparable to $\mathrm{Pt}$ nanoparticles [10]. Other research has looked at reducing the amount of Pt used by employing Pt and other metal clusters (1-100 atoms), which have shown improved hydrogen production rates [11,12].

Despite the popularity of using $\mathrm{Pt}$ as the co-catalyst there is little consensus on the best practise of $\mathrm{Pt}$ deposition. This makes it difficult to compare photocatalysis results between research groups due to the disparity in Pt deposition method. In contrast, Aeroxide ${ }^{\circledR}$ P25 (Evonik Degussa GmbH (Essen, Germany), "P25") is a commercial source of $\mathrm{TiO}_{2}$ which can be reliably used worldwide as an active and reliable photocatalyst and as a research benchmark [13].

Pt nanoparticles are most commonly produced via photodeposition or impregnation [2]. Photodeposition involves suspending the photocatalyst in a solution containing a Pt precursor (such as $\mathrm{H}_{2} \mathrm{PtCl}_{6}$ ) with a hole scavenger (methanol, $\mathrm{Na}_{2} \mathrm{CO}_{3}$ ) and illuminating with light that can excite the photocatalyst. The suspension is stirred and the reaction allowed to continue for $1-5 \mathrm{~h}$ before being collected and washed via repeated centrifuge steps and then dried in an oven. Pt impregnation involves mixing a Pt precursor with photocatalyst in a crucible with a small volume of solvent. The mixture is heated above the boiling temperature of the solvent until dry. The sample is ready to use directly. 
Pt impregnation is far simpler but there is little control over the Pt nanoparticle size or interface with the photocatalyst. Photodeposition is far more time-consuming but produces a narrower size range of nanoparticles and, since the photocatalyst is responsible for the reduction, there is a strong interface between the $\mathrm{Pt}$ and the photocatalyst.

In this manuscript we present a method to prepare a Pt nanocluster (Pt-nc) co-catalyst on P25 via the impregnation method using a commercial Pt suspension typically used for electrocatalytic iodine reduction. We show that the Pt-nc co-catalyst outperforms photodeposited Pt nanoparticles (Pt-np) in gas phase photocatalytic $\mathrm{D}_{2}$ evolution from heavy water. This method, using commercially available sources for both photocatalyst and co-catalyst, could be used as a benchmark in comparing photocatalyst performance.

\section{Materials and Methods}

\subsection{Platinum Photodeposition (P25-Pt-np)}

Within a custom-made quartz lidded sealed container, commercial $\mathrm{TiO}_{2}$ powder $\left(50 \mathrm{mg}\right.$, Aeroxide ${ }^{\circledR}$ P25, Evonik Degussa GmbH, "P25", Sigma-Aldrich, Castle Hill, Australia) was dispersed into a $50 \mathrm{~mL}$ aqueous suspension of $1 \mathrm{M}$ methanol (99.8\%, Chem-Supply, Gillman, Australia) via sonication for $10 \mathrm{~min}$. To this stirred suspension, $256 \mu \mathrm{L}$ of $0.01 \mathrm{M} \mathrm{Pt}\left(25.8 \mathrm{mg}, \mathrm{K}_{2} \mathrm{PtCl}_{6}\right.$, Sigma-Aldrich, Australia) aqueous suspension was added to prepare a $1 \mathrm{wt} \% \mathrm{Pt}$ on $\mathrm{TiO}_{2}$ sample. With stirring and in an ice bath, the sample was illuminated with ultraviolet (UV) irradiation ( $365 \mathrm{~nm}$, UVATA, Shanghai, China) set to an approximate power of $2 \mathrm{~W} \mathrm{~cm}^{-2}$ for $30 \mathrm{~min}$. The now slightly grey sample was repeatedly collected and washed with water $(\times 2)$ and ethanol $(\times 2,100 \%$ undenatured, Chem-Supply, Gillman Australia) via centrifuge (Sigma 2-16P, John Morris, Chatswood, Australia) at $5304 \mathrm{~g}$, before being dried in an oven at $100{ }^{\circ} \mathrm{C}$ overnight. Samples produced by this method are referred to as P25-Pt-np.

\subsection{Platinum Impregnation (P25-Pt-nc)}

To prepare $1 \mathrm{wt} \% \mathrm{Pt} / \mathrm{TiO}_{2}$ via impregnation, $\mathrm{P} 25$ powder $(10 \mathrm{mg})$ was mixed with $102 \mu \mathrm{L} \mathrm{Pt}$ cluster suspension (CELS, Counter Electrode Solution, MS006220, DyeSol, Queanbeyan, Australia, see note $)$ and $0.9 \mathrm{~mL}$ methanol in an alumina crucible. The slurry was sonicated for $10 \mathrm{~min}$ before being placed in the centre of a muffle furnace (S.E.M Pty. Ltd., Adelaide, Australia). The temperature was increased at $1{ }^{\circ} \mathrm{C} \mathrm{min}-1$ until $100{ }^{\circ} \mathrm{C}$ and then heated to $450{ }^{\circ} \mathrm{C}$ without ramping control. The sample was left at $450^{\circ} \mathrm{C}$, in air for $30 \mathrm{~min}$ before being cooled to RT. The sample was used without further purification. Other $w t \%$ of $\mathrm{Pt}$ were obtained by varying volume of CELS added (e.g., $204 \mu \mathrm{L}$ for $2 \mathrm{wt} \%$ ) and volume of methanol such that the total volume was $1 \mathrm{~mL}$ (e.g., $0.8 \mathrm{~mL}$ for $2 \mathrm{wt} \%$ ). Samples produced by this method are referred to as P25-Pt-nc.

*Note: CELS contains $0.005 \mathrm{M} \mathrm{Pt}$ and a trade secret mix of additives to produce Pt clusters (personal communication with Greatcell Solar, formerly known as Dyesol).

\subsection{Photocatalytic Discs}

The photocatalysts were deposited onto $1.3 \mathrm{~cm}^{2}$ glass microfibre discs (Type A/E, Pall, Port Washington, NY, USA) for photocatalytic testing; $5 \mathrm{mg}$ of photocatalyst (to prepare 3 photocatalytic discs) was dispersed in $3 \mathrm{~mL} \mathrm{H}_{2} \mathrm{O}$ via sonication for $10 \mathrm{~min}$. The suspension was then dropped onto pre-weighed microfibre discs on a hotplate in a fumehood at $50{ }^{\circ} \mathrm{C}$. The suspension was left to dry before the dropping procedure was repeated until all suspension was consumed. The sample left to dry overnight and then weighed. Typical sample weights were $1.2-1.8 \mathrm{mg}(\sim 1.5 \mathrm{mg})$. The effect of photocatalyst loading was also investigated by increasing the concentration of the photocatalyst to prepare samples of $\sim 3 \mathrm{mg}$ and $\sim 5 \mathrm{mg}$. 


\subsection{Characterization}

Scanning transmission electron microscopy (STEM) imaging and energy-dispersive X-ray spectroscopy (EDS) were performed on a FEI Titan Themis S/TEM instrument (Thermo Fisher Scientific, Waltham, MA, USA), operated at $200 \mathrm{keV}$. The STEM probe was aberration-corrected, enabling sub-angstrom spatial resolution, and high-angle annular dark field (HAADF) images were obtained with a collection angle greater than $50 \mathrm{mrad}$. The imaging technique is referred to as TEM in the manuscript for simplicity.

Scanning electron microscopy (SEM) and EDS were obtained using a FEI (USA) Quanta 450 SEM equipped with an Oxford Instruments (Abingdon, UK) EDAX detector.

The UV-vis reflectance spectra were measured using a UV-Vis spectrophotometer (Cary 5000, Agilent, Santa Clara, CA, USA) with a Praying Mantis Sample Kit (DRP-SAP, Harrick Scientific products Inc., Pleasantville, NY, USA). The powdered samples were pressed with a spatula onto the sample holder.

X-ray diffraction (XRD) was obtained with Co irradiation $(\lambda=1.78896 \mathrm{~nm})$ using a D4 Endeavor diffractometer (Bruker, Billerica, MA, USA). Data was obtained from 2theta 20-80 with step size of 0.02 .

Attenuated total reflection Fourier transform infrared (ATR-FTIR, Perkin-Elmer) spectroscopy was obtained with a ZnSe crystal. Spectra were collected from $500-4000 \mathrm{~cm}^{-1}$ at $4 \mathrm{~cm}^{-1}$ step size with 8 accumulations. A background of air and clean crystal was used for each scan.

\subsection{Photocatalysis}

Photocatalytic $\mathrm{D}_{2}$ evolution from heavy water $\left(\mathrm{D}_{2} \mathrm{O}\right)$ was carried out in the gas phase using a batch reactor described in detail previously [14]. $\mathrm{D}_{2} \mathrm{O}$ was investigated to ensure products were not derived from sacrificial reagents or the catalyst itself. The general procedure for each experiment was to load the photocatalyst (on the microfibre disc) into the reaction cell, and evacuate to high vacuum under heating to $150{ }^{\circ} \mathrm{C}$ for $1 \mathrm{~h}$ before isolating the cell from vacuum. The reaction was carried out at $150{ }^{\circ} \mathrm{C}$, which we have found to reduce noise in the produced data. $\mathrm{D}_{2} \mathrm{O}$ (heavy water, $99.9 \%$, Cambridge Isotopes Laboratories Inc., Cambridge, MA, USA), with purity confirmed by ATR-FTIR (Figure S1) [15], is then introduced by opening a valve connecting the reaction cell with a small volume of $\mathrm{D}_{2} \mathrm{O}$ in a gas tight glass bulb. Under these conditions, approximately 17 mbar of $\mathrm{D}_{2} \mathrm{O}$ vapour enters the reaction cell (which has volume of $3.8 \mathrm{~mL}$ ). The valve connecting the reaction cell to the $\mathrm{D}_{2} \mathrm{O}$ is closed and the reaction cell is filled to 1000 mbar with nitrogen $(99.999 \%$, UHP, BOC, Adelaide, Australia).

The contents of the reaction cell are analysed by a residual gas analyser (RGA, RGA200, SRS Stanford Research System, Sunnyvale, CA, USA) and is delivered from the reaction cell gas via a pulse nozzle. The pulse nozzle is controlled via a LabView program with proportional-integral-derivative (PID) control to maintain a constant RGA pressure of $2 \times 10^{-6}$ Torr. This correlates to a reaction cell pressure drop of $\sim 0.5 \mathrm{mbar}^{-1} \mathrm{~min}^{-1}$. The RGA determines the relative pressure of constituents in the $\mathrm{m} / \mathrm{z}$ range of $1-65 \mathrm{amu} \mathrm{Q}^{-1}$, with an entire scan occurring every $67 \mathrm{~s}$.

The reaction cell constituents are monitored for at least $30 \mathrm{~min}$ in dark to obtain the background value before illuminating the sample with UV light-emitting diode (LED) light (368 $\mathrm{nm}, 20.2 \mathrm{~mW} \cdot \mathrm{cm}^{-2}$, $17 \mathrm{~cm}$ above sample, Shenzhen UVET, UV50-S, China). The photocatalytic products are monitored for 30-60 min. The sample reaction cell is then evacuated for $30 \mathrm{~min}$ before the process is repeated 2 or more times with the same sample. The recorded values from the RGA are converted into moles produced from calibration procedures and is described in detail elsewhere [14].

Statistical analysis of production rates were carried out using Matlab R2016b. The data are presented as box and whisker plots. On each box, the central mark indicates the median, and the bottom and top edges of the box indicate the 25th and 75th percentiles, respectively. The whiskers extend to the most extreme data points not considered outliers (Matlab documentation). 


\section{Results}

\subsection{Transmission Electron Microscopy (TEM) Analysis of Pt on P25}

TEM of the photodeposited and impregnated samples are presented in Figures 2 and 3. The photodeposited Pt (P25-Pt-np, Figure 2) shows a broad distribution of nanoparticle diameters centred at $0.96 \mathrm{~nm}$ with standard deviation of $0.38 \mathrm{~nm}$. The observed broad size range is typical for the procedure followed. The EDS plots in Figure 2c confirm that the particles observed (with higher contrast) are Pt.

The impregnated Pt sample (P25-Pt-nc, Figure 3) shows much smaller features with similar contrast to the photodeposited Pt nanoparticles. In fact, the Pt appears to be deposited in monomer or dimer clusters onto the $\mathrm{TiO}_{2}$ surface (digital zoom insets in Figure 3d,e). Particle size analysis shows an average diameter of $0.16 \mathrm{~nm}$ with a standard deviation of $0.04 \mathrm{~nm}$. Due to the small size of the $\mathrm{Pt}$ clusters, they are observed only on the edge of the $\mathrm{TiO}_{2}$ nanoparticles. EDS confirms the clusters are made from Pt with single spot EDS spectra (Figure 3c) in which the spectrum of the Pt cluster was only obtained from 1-3 scans before the Pt atom either moved or was damaged by the electron beam.

Pt has an atomic radii of $0.135 \mathrm{~nm}$ [16], and the apparent underestimation of Pt diameter in the TEM images likely arises from the difference in electron density observed from TEM and calculated atomic radii. Other example of TEM images of Pt atoms show similar structures and measured diameters of less than $0.2 \mathrm{~nm}[17,18]$.
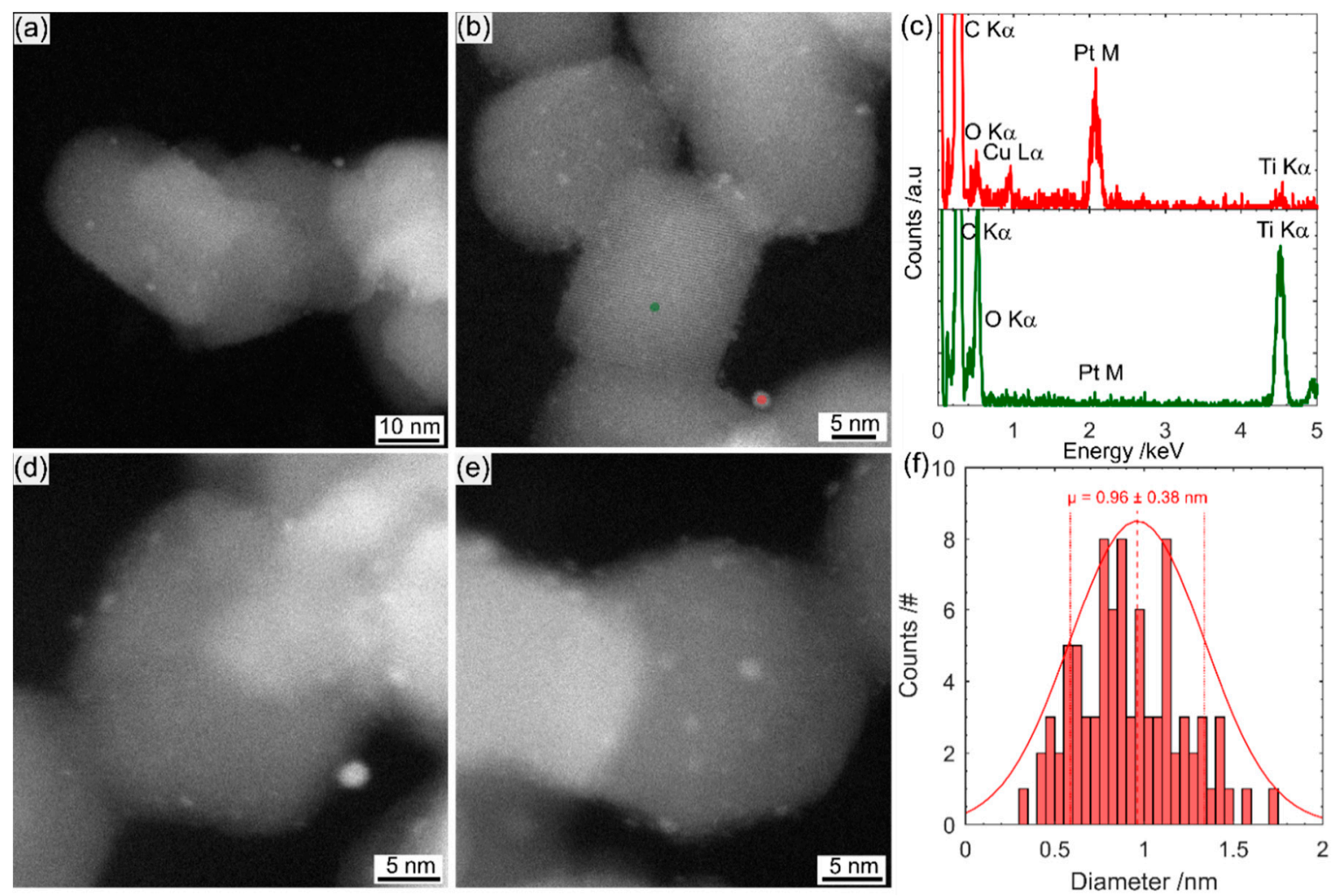

Figure 2. Transmission electron microscope (TEM) images (a,b,d,e), energy-dispersive X-ray spectroscopy (EDS) plots (c) and particle size histogram (f) for P25-Pt-np samples produced via Pt photodeposition. The EDS plots (c) are from points highlighted in (b) with green and red circle corresponding to the green $\left(\mathrm{TiO}_{2}\right.$ only) and red $\left(\mathrm{Pt} \mathrm{np}\right.$ on $\left.\mathrm{TiO}_{2}\right)$ EDS spectra. Pt np diameter distribution (f) with normal distribution analysis obtained from $>5$ images and 89 measured nanoparticles.

The Pt suspension used for impregnation is claimed to produce "Pt clusters" by the manufacturer. Under the conditions described here, it produced Pt monomer and small (2-5 atom clusters). Other methods to produce $\mathrm{Pt}$ monomer on surfaces have used suspensions of $\mathrm{H}_{2} \mathrm{PtCl}_{6}$ followed by thermal 
evaporation [18]. This previous study found a maximum $\mathrm{Pt}$ loading of $0.16 \mathrm{wt} \%$ before larger $\mathrm{Pt}$ nanoparticles were observed. Using CELS counter electrode solution, we have obtained Pt samples consisting of $\mathrm{Pt}$ monomers with higher wt\% (i.e., 1\% herein). The observed higher loading may also correlate to substrate surface area and surface energy.
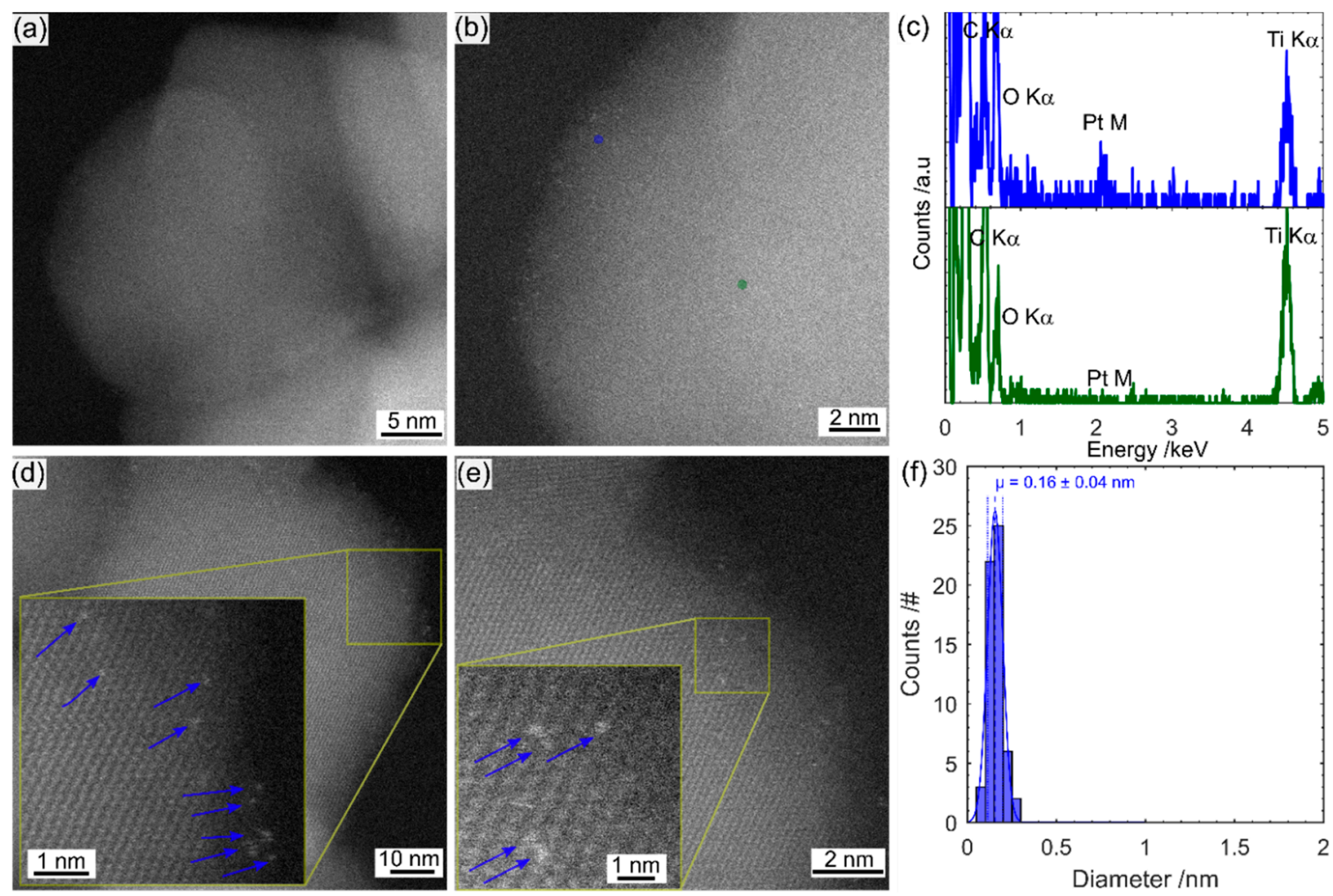

Figure 3. TEM images (a,b,d,e), EDS plots (c) and particle size histogram (f) for P25-Pt-nc samples produced via $\mathrm{Pt}$ impregnation. The EDS plots (c) are from points highlighted in (b) with green and blue circle corresponding to the green $\left(\mathrm{TiO}_{2}\right.$ only) and red $\left(\mathrm{Pt} \mathrm{nc}\right.$ on $\left.\mathrm{TiO}_{2}\right)$ EDS spectra. Pt nc diameter distribution (f) with normal distribution analysis obtained from $>5$ images an 58 measured nanoparticles. Arrows in the inset of (d,e) highlight single Pt atoms.

\subsection{Ultraviolet-Visible (UV-Vis) Reflectance and X-Ray Diffraction (XRD)}

After confirmation of Pt loading by TEM, optical and crystallography analysis was completed to determine if the different Pt deposition methods resulted in changes to optical absorption or crystal structure of the $\mathrm{TiO}_{2}-\mathrm{Pt}$ photocatalysts. UV-Vis reflectance measurements (Figure 4a) show that the metallic nanoparticles increase the visible light absorbance of the photocatalysts. In contrast the Pt nanoclusters show only a slight increase in visible light absorbance. The parasitic visible light absorbance by the co-catalyst is an issue in visible-light active photocatalysis where photons are absorbed by the co-catalyst instead of the semiconductor. The reflectance measured at the wavelength used for photocatalytic reactions measured herein $(365 \mathrm{~nm})$ is unchanged between samples. The UV-Vis reflectance measurements have shown a decrease in visible light absorption for the Pt-nc loaded sample relative to the Pt-np loaded sample, and this may prove to be beneficial in visible light photocatalytic reactions in the future.

P25 is a combination of $\mathrm{TiO}_{2}$ in the rutile and anatase crystal phases as well as amorphous $\mathrm{TiO}_{2}$ [13]. The high photocatalytic activity of P25 is attributed to the small particle size $(\sim 21 \mathrm{~nm})$ and this combination of crystal phases. Anatase $\mathrm{TiO}_{2}$ undergoes a phase change to rutile at approximately $600{ }^{\circ} \mathrm{C}$ but this is dependent on a number of environmental factors [19]. To ensure the different $\mathrm{Pt}$ deposition methods (photoillumination or impregnation $@ 450{ }^{\circ} \mathrm{C}$ ) did not alter the underlying crystal structure of P25, XRD was completed and the results are present in Figure $4 \mathrm{~b}$. Both samples show 
identical spectra with a mixture of anatase $(A)$ and rutile (R), confirming that the different Pt loading method did not alter the crystal structure of $\mathrm{TiO}_{2}$.
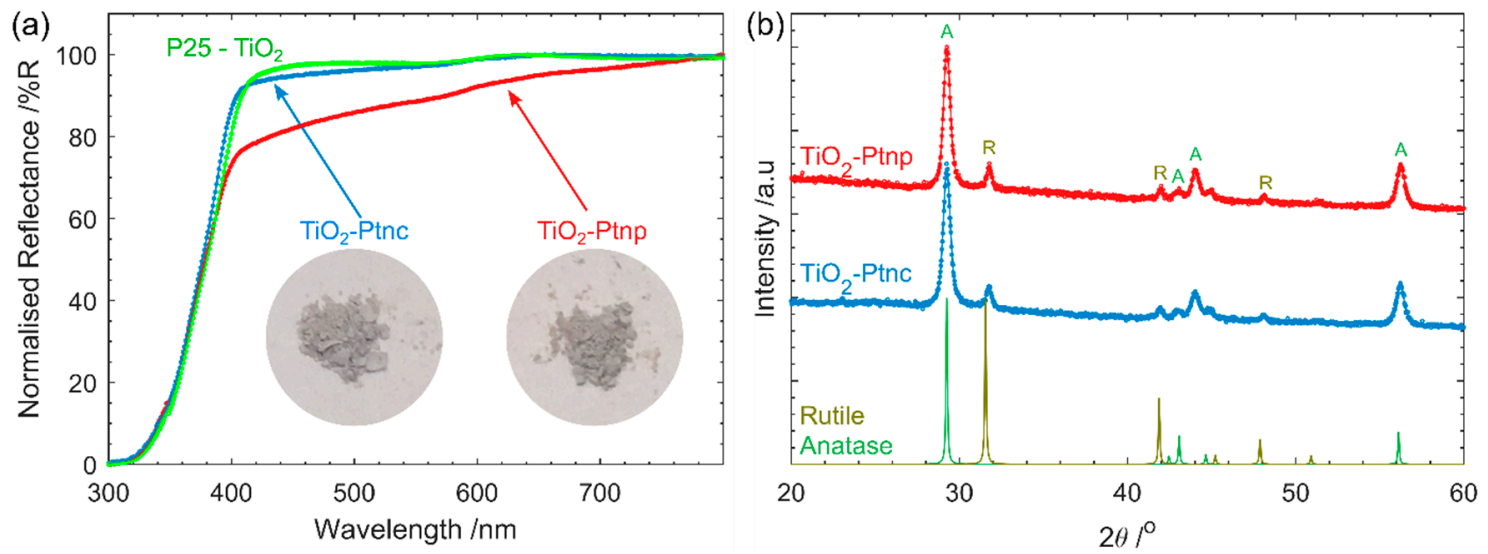

Figure 4. Optical and crystallography properties of the samples produced showing (a) ultraviolet-visible (UV-vis) reflectance of the powdered samples (inset shows digital photographs) and (b) X-ray diffraction (XRD) patterns of P25 $\left(\mathrm{TiO}_{2}\right)$ bare and with $\mathrm{Pt}$ nanoparticles and nanoclusters. Co irradiation source, $\lambda=1.78896 \mathrm{~nm}$. Anatase (mp-390, I4 $1 / \mathrm{mnd})$ and rutile (mp-2657, $\mathrm{P}_{2} / \mathrm{mnm}$ ) diffraction patterns calculated from crystallographic information files obtained from the materialsproject.org.

\subsection{Photocatalytic Performance}

Photocatalytic $\mathrm{D}_{2}$ evolution from $\mathrm{D}_{2} \mathrm{O}$ was completed in the gas phase, with UV illumination ( $365 \mathrm{~nm}, 20.2 \mathrm{~mW} \cdot \mathrm{cm}^{-2}$ at $1 \mathrm{bar}$ and $150{ }^{\circ} \mathrm{C}$ ). These conditions were chosen to emulate steam as the water source. Production of $\mathrm{D}_{2}$ for a typical photocatalytic reaction is presented in Figure 5. Upon UV illumination, there is an immediate rise in $\mathrm{D}_{2}$ measured. After 10-15 min the rate decreases slightly but becomes more linear. These two reaction rates are shown in the Figure and correspond to a 'peak' production rate and 'steady' production rate. For each sample there are 3 consecutive reactions of the same photocatalytic disc, which was evacuated between reactions. Typically the peak production rate is higher the first time the photocatalyst is used but becomes nearer to the steady production rate with repeated reactions. This observation is more obvious for the reaction in Figure $5 \mathrm{~b}$ for a P25-Pt-nc photocatalyst. This high peak production for the first reaction also occurs with a concurrent production of $\mathrm{CO}_{2}(\mathrm{~m} / \mathrm{z}=44$, Figure S3). It appears that residual carbon on the photocatalytic disc is acting as a hole scavenger (sacrificial reagent) and promotes the photocatalytic reaction. When the residual carbon is used up $\left(\mathrm{CO}_{2}\right.$ no longer produced), the photocatalyst production rate returns to its native steady production. Consequently, the peak production rates between samples varied significantly (Table 1). The measured production rates are much more consistent when comparing the steady production rates, and these will be used for discussion. $\mathrm{No}_{2}$ or $\mathrm{CO}_{2}$ was observed in photocatalytic reactions without the Pt co-catalyst.

Figure 6 and Table 1 compare the steady production rate of the different photocatalysts measured. The photodeposited Pt-np were investigated at a loading of $1 \mathrm{wt} \%$ to emulate the common procedure in literature. Production rate values are compared in values of $\mathrm{nmol} \mathrm{h}^{-1}$ due to a small correlation of photocatalytic activity with photocatalyst mass on the prepared discs (vide infra). The Pt-nc samples were prepared to a matching $1 \mathrm{wt} \%$ (assuming all $\mathrm{Pt}$ in starting material is attached) and then the loading of Pt-nc was optimized for a $\mathrm{D}_{2}$ production rate. The $\mathrm{D}_{2}$ production rate for all $\mathrm{Pt}$-nc samples outperformed the Pt-np cocatalysts; the mean $\mathrm{D}_{2}$ steady production rate for Pt-np cocatalyst was $22 \pm 6 \mathrm{nmol} \mathrm{h}^{-1}$ compared to the Pt-nc- $2 \mathrm{wt} \%$ which achieved $37 \pm 14 \mathrm{nmol} \mathrm{h}^{-1}$. To determine the production rate per unit mass of precious metal, the Pt loading was determined by EDS. More than 10 individual areas of the samples were characterised by EDS and the results are summarised 
in Figure S4 and Table 1. The Pt yield of all samples is below $100 \%$ with photodeposition producing the highest yield (86\%) while impregnation has yields of 25,16 and $14 \%$ for $1,2,4 \mathrm{wt} \%$, respectively. When we compare $\mathrm{D}_{2}$ production rates normalised to mass of Pt on the photocatalytic disc (Table 1 ), we see that the nc samples far outperform Pt nps by factors of 2-5.
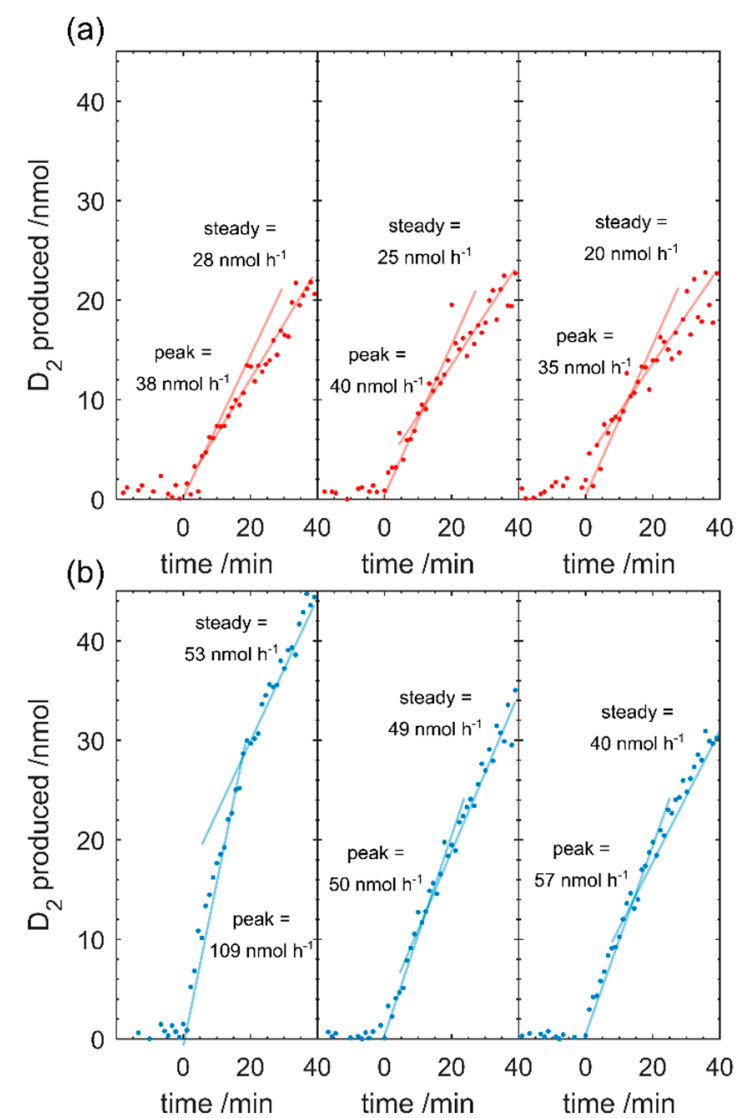

Figure 5. Photocatalytic production of $\mathrm{D}_{2}(m / z=4)$ for (a) P25-Pt-np-1 wt\% photocatalyst and (b) P25-Pt-nc-2 wt \% photocatalyst. Each shows repeated experiments for the same photocatalytic disc $\left(1.3 \mathrm{~cm}^{2}\right)$ loaded with $\sim 1.5 \mathrm{mg}$ photocatalyst, and reaction cell evacuated between experiments. Light source is UV light-emitting diode (LED), $365 \mathrm{~nm}, 20.2 \mathrm{~mW} \cdot \mathrm{cm}^{-2}$.

Table 1. Photocatalytic $\mathrm{D}_{2}$ peak and steady production rates for the photocatalysts studied with $\mathrm{Pt}$ mass and steady production rate per gram of Pt on the sample. All data are from at least 3 individual photocatalytic discs $\left(\sim 1.5 \mathrm{mg}, 1.3 \mathrm{~cm}^{2}\right)$ with each disc repeated 3 times.

\begin{tabular}{|c|c|c|c|c|}
\hline Photocatalyst & $\begin{array}{l}\text { Peak } D_{2} \text { Production } \\
\text { Rate }\left(\text { nmol h }^{-1}\right)\end{array}$ & $\begin{array}{l}\text { Steady } D_{2} \\
\text { Production Rate } \\
\left(\text { nmol h h }^{-1}\right)\end{array}$ & $\begin{array}{l}\text { Pt Loading } \\
\quad(w t \%)\end{array}$ & $\begin{array}{l}\text { Steady } D_{2} \text { Production } \\
\text { Rate per Mass Pt } \\
\left(\mu \mathrm{mol} \mathrm{h} \mathrm{h}^{-1} \mathrm{~g}^{-1}\right)\end{array}$ \\
\hline P25-Pt-np (1 wt\%) & $37 \pm 15$ & $22 \pm 6$ & $0.86 \pm 0.25$ & 2,549 \\
\hline P25-Pt-nc-1 wt\% & $51 \pm 33$ & $30 \pm 7$ & $0.25 \pm 0.23$ & 11,965 \\
\hline P25-Pt-nc-2 wt\% & $53 \pm 26$ & $37 \pm 14$ & $0.33 \pm 0.17$ & 11,088 \\
\hline P25-Pt-nc-4 wt\% & $67 \pm 43$ & $31 \pm 9$ & $0.57 \pm 0.38$ & 5,411 \\
\hline
\end{tabular}

In addition to the peak reaction rate decreasing with repeated reactions due to the consumption of adventitious carbon, the steady reaction rate also decreased, but to a lesser degree. Figure 7 shows the steady production rate for Pt-np and Pt-nc photocatalysts normalised to 1 for each run. The Pt-np photocatalyst have higher recyclability with 2 of the samples tested achieving at least $100 \%$ of their initial production rate for the third repeat. In comparison, all of the Pt-nc samples tested degrade with repeated testing with an average of $67 \%$ of the initial steady production rate achieved for the third reaction. The source of the degradation needs to be investigated further but may result from faster 
poisoning of the smaller Pt catalyst from $\mathrm{CO} / \mathrm{CO}_{2}$ present in the system. The Pt clusters may also agglomerate during testing which may also reduce the performance. Photographs of the photocatalytic discs before and after testing (Figure S6) show a significant darkening of the discs which may suggest agglomeration is occurring.

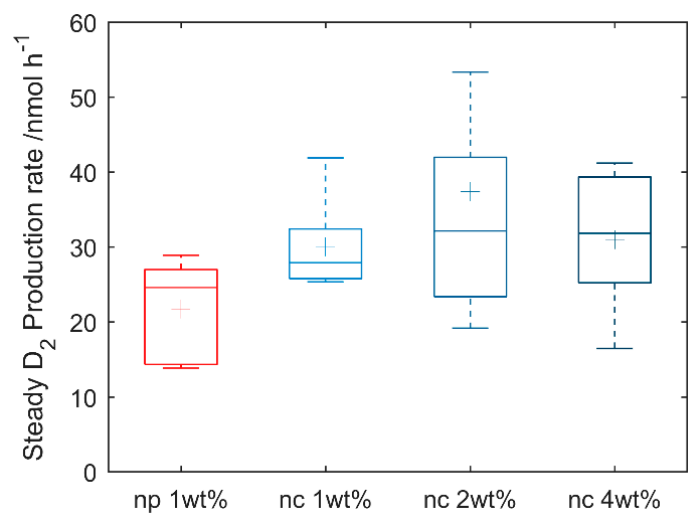

Figure 6. Box and whisker plots of steady $\mathrm{D}_{2}$ production rate for photocatalysts tested.
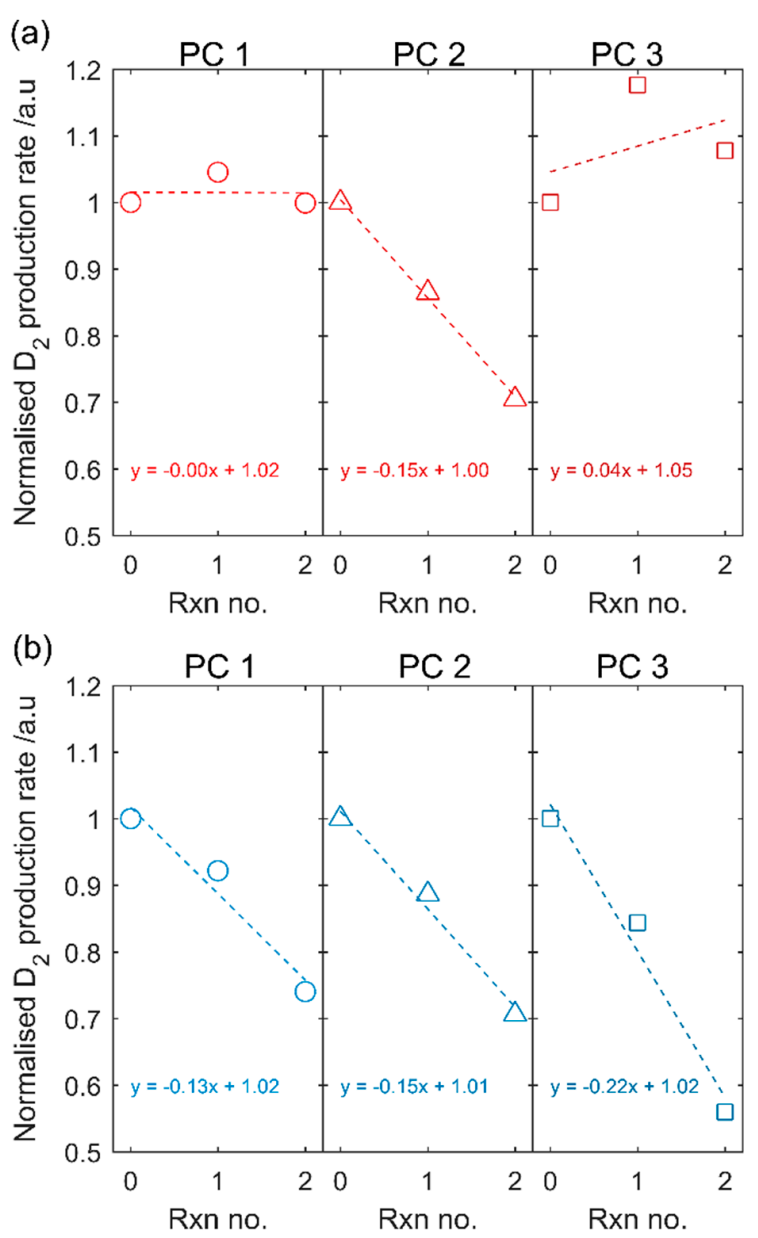

Figure 7. Recycling of photocatalytic discs for (a) P25-Pt-np- $1 \mathrm{wt} \%$ and (b) P25-Pt-nc- 2 wt $\%$. Each graph shows normalised $\mathrm{D}_{2}$ photocatalytic production rate for 3 repeated reactions and 3 unique photocatalytic discs (PC 1-3).

The data have been compared using units of $\mathrm{nmol} \mathrm{h}^{-1}$. Each sample had the same area $\left(1.3 \mathrm{~cm}^{2}\right)$ but the mass of each sample varied. The goal mass was $1.5 \mathrm{mg}$ per sample; however, the dropcasting deposition process onto porous microfibre mats resulted in sample mass variation 
of up to $1 \mathrm{mg}$. To investigate whether the data should be presented in $\mathrm{nmol} \mathrm{h}-1$ or $\mu \mathrm{mol} \mathrm{h}^{-1} \mathrm{~g}^{-1}$ a series of experiments were conducted with different mass loading of the photocatalyst. The samples were all identical photocatalyst (P25-Pt-nc- $2 \mathrm{wt} \%$ ) but were dropcast from a solution with different concentrations to prepare $\sim 1.5 \mathrm{mg}, \sim 3 \mathrm{mg}$ and $\sim 5 \mathrm{mg}$ samples. The results for photocatalytic $\mathrm{D}_{2}$ production are summarized in Figure S5. When using unit of $\mathrm{nmol} \mathrm{h}^{-1}$, the samples show similar production rates. However, when the data are presented in $\mu \mathrm{mol} \mathrm{h}^{-1} \mathrm{~g}^{-1}$ the data scales significantly with sample mass. This comparison shows that (1) ideally the photocatalysts should be the same mass and (2) if this is not possible, data should be compared without dividing by sample mass.

\section{Discussion}

The much simpler Pt impregnation method, using a commercially available Pt precursor solution has produced a much smaller size range of $\mathrm{Pt}$ on $\mathrm{TiO}_{2}$ than photodeposited Pt. The Pt-nc sample absorbs significantly less visible light and has not altered the $\mathrm{TiO}_{2}$ crystal structure. Photocatalysis results yield a higher $\mathrm{D}_{2}$ production rate for gas phase $\mathrm{D}_{2} \mathrm{O}$ splitting. Much like how P25 has become the benchmark photocatalyst, a reliable method to produce Pt co-catalysts has been required in the field. Pt clusters deposited using the method described here is an ideal candidate. Many of the advantages of P25 as a benchmark also apply to Pt clusters obtained from CELS Pt suspension. The material can be purchased worldwide, does not require further processing, and is deposited using only mixing and heat. In contrast, Pt photodeposition is completed from Pt precursors purchased from a range of sources, with varying purities. The $\mathrm{Pt}$ is then photodeposited in a solution containing one of many hole-scavengers with light of varying wavelength and intensity, with the end result of $\mathrm{Pt}$ with varying size and, therefore, co-catalyst ability.

A drawback observed is the reduced recyclability of the Pt-nc co-catalyst. The conditions used for the gas phase photocatalysis experiments are extreme for photocatalysis reactions and include a high vacuum and $150{ }^{\circ} \mathrm{C}$. Optimisation of catalyst loading or photocatalysis experiments under milder conditions (e.g., $\mathrm{T}<150{ }^{\circ} \mathrm{C}$, visible light) may lead to higher recyclability of the Pt-nc co-catalysts.

An advantage to the Pt-nc co-catalyst that was not investigated is the reduced visible light absorption compared to Pt-nps. This advantage may prove to be an asset when assessing visible light active photocatalysts where parasitic light absorption by co-catalysts is often cited as a source of reduction in performance $[20,21]$.

\section{Conclusions}

A method to prepare Pt nanoclusters on $\mathrm{TiO}_{2}$ for use in photocatalysis has been presented. Characterisation of the photocatalysts found $\mathrm{Pt}$ was deposited in monomer or small cluster (1-5 atoms) onto $\mathrm{TiO}_{2}$ without altering the optical or crystallographic properties of the semiconductor. Photocatalytic water splitting from the Pt nanocluster co-catalyst showed higher $\mathrm{D}_{2}$ production rates compared to Pt produced via photodeposition.

The method uses only commercial sources and should be repeatable worldwide, and therefore is recommended to be used as a benchmark in photocatalytic studies using $\mathrm{Pt}$ as the co-catalyst.

Supplementary Materials: The following are available online at http:/ /www.mdpi.com/2311-5629/4/4/64/s1, Figure S1: Attenuated total reflection Fourier transform infrared (ATR-FTIR) spectra showing absorbance of $\mathrm{H}_{2} \mathrm{O}$ (navy series) and $\mathrm{D}_{2} \mathrm{O}$ (purple series) placed onto the ATR crystal which shows that the $\mathrm{D}_{2} \mathrm{O}$ is pure. Figure S2: ATR-FTIR spectra of glass microfibre discs loading with increasing mass/area P25-Ptnc photocatalyst showing bare $(0 \mathrm{mg} / \mathrm{cm})$, low $(\sim 1.5 \mathrm{mg} / \mathrm{cm})$, medium $(\sim 3 \mathrm{mg} / \mathrm{cm})$ and high $(\sim 5 \mathrm{mg} / \mathrm{cm})$ loading. From the disappearance of the Si-O stretch at $1000 \mathrm{~cm}^{-1}$, the surface is coated for the medium and high loadings and the low loading has a very small fraction of uncoated surface. Figure S3: Repeated photocatalysis experiments for a Pt-nc sample $\left(1 \mathrm{wt} \%\right.$ ) showing the production of $\mathrm{D}_{2}$ (purple, $\left.m / z=4\right), \mathrm{O}_{2}$ (grey, $m / z=32$ ) and $\mathrm{CO}_{2}$ (brown, $m / z=44$ ) for repeated experiments. In the first experiment, $\mathrm{CO}_{2}$ is produced and $\mathrm{O}_{2}$ is consumed. In subsequent experiments $\mathrm{CO}_{2}$ and $\mathrm{O}_{2}$ are not produced or consumed. Investigation is continuing to determine why $\mathrm{O}_{2}$ is not produced. Figure S4. Pt mass loading \% for each sample determined by EDS. $>10$ individual areas were investigated by EDS for each sample. Figure S5: Comparison of $\mathrm{D}_{2}$ production rates with photocatalyst (P25-Ptnc-2 wt $\%$ ) loading. The data are presented with (upper figure) and without (lower figure) dividing by photocatalyst mass. Figure S6: 
Digital photographs of P25-Pt-nc-1 wt\% photocatalytic disc (a) before and (b) after 3 repeated UV photocatalytic $\mathrm{D}_{2}$ production experiments.

Author Contributions: Conceptualization, C.J.S., M.B. and G.F.M.; Data curation, C.J.S. and J.F.A.; Formal analysis, C.J.S.; Funding acquisition, G.F.M.; Investigation, C.J.S.; Methodology, C.J.S., J.F.A. and M.B.; Resources, M.B. and G.F.M.; Supervision, G.F.M.; Visualization, C.J.S.; Writing-original draft, C.J.S.; Writing-review and editing, C.J.S., J.F.A., M.B. and G.F.M.

Funding: This research received no external funding.

Acknowledgments: This work is supported by the South Australian node of the Australian Microscopy and Microanalysis Research Facility (AMMRF). We thank the University of Adelaide for a University Fellowship (CJS, 2018) and equipment grant. We thank Prof. Christopher Sumby (University of Adelaide) and the Bragg Crystallography Facility for access to XRD and Ashley Slattery and Adelaide Microscopy for STEM analysis.

Conflicts of Interest: The authors declare no conflict of interest.

\section{References}

1. Rodriguez, C.A.; Modestino, M.A.; Psaltis, D.; Moser, C. Design and cost considerations for practical solar-hydrogen generators. Energy Environ. Sci. 2014, 7, 3828-3835. [CrossRef]

2. Wenderich, K.; Mul, G. Methods, mechanism, and applications of photodeposition in photocatalysis: A review. Chem. Rev. 2016, 116, 14587-14619. [CrossRef] [PubMed]

3. Shearer, C.J.; Cherevan, A.; Eder, D. Application and future challenges of functional nanocarbon hybrids. Adv. Mater. 2014, 26, 2295-2318. [CrossRef] [PubMed]

4. Linsebigler, A.L.; Lu, G.; Yates, J.T. Photocatalysis on $\mathrm{TiO}_{2}$ surfaces: Principles, mechanisms, and selected results. Chem. Rev. 1995, 95, 735-758. [CrossRef]

5. Heller, A.; Aharon-Shalom, E.; Bonner, W.A.; Miller, B. Hydrogen-evolving semiconductor photocathodes: Nature of the junction and function of the platinum group metal catalyst. J. Am. Chem. Soc. 1982, 104, 6942-6948. [CrossRef]

6. Seh, Z.W.; Kibsgaard, J.; Dickens, C.F.; Chorkendorff, I.; Nørskov, J.K.; Jaramillo, T.F. Combining theory and experiment in electrocatalysis: Insights into materials design. Science 2017, 355. [CrossRef] [PubMed]

7. Jiao, Y.; Zheng, Y.; Jaroniec, M.; Qiao, S.Z. Design of electrocatalysts for oxygen- and hydrogen-involving energy conversion reactions. Chem. Soc. Rev. 2015, 44, 2060-2086. [CrossRef] [PubMed]

8. Pinaud, B.A.; Benck, J.D.; Seitz, L.C.; Forman, A.J.; Chen, Z.; Deutsch, T.G.; James, B.D.; Baum, K.N.; Baum, G.N.; Ardo, S.; et al. Technical and economic feasibility of centralized facilities for solar hydrogen production via photocatalysis and photoelectrochemistry. Energy Environ. Sci. 2013, 6, 1983-2002. [CrossRef]

9. Dumortier, M.; Tembhurne, S.; Haussener, S. Holistic design guidelines for solar hydrogen production by photo-electrochemical routes. Energy Environ. Sci. 2015, 8, 3614-3628. [CrossRef]

10. Ran, J.; Zhang, J.; Yu, J.; Jaroniec, M.; Qiao, S.Z. Earth-abundant cocatalysts for semiconductor-based photocatalytic water splitting. Chem. Soc. Rev. 2014, 43, 7787-7812. [CrossRef] [PubMed]

11. Berr, M.J.; Schweinberger, F.F.; Döblinger, M.; Sanwald, K.E.; Wolff, C.; Breimeier, J.; Crampton, A.S.; Ridge, C.J.; Tschurl, M.; Heiz, U.; et al. Size-selected subnanometer cluster catalysts on semiconductor nanocrystal films for atomic scale insight into photocatalysis. Nano Lett. 2012, 12, 5903-5906. [CrossRef] [PubMed]

12. Kowalska, E.; Remita, H.; Colbeau-Justin, C.; Hupka, J.; Belloni, J. Modification of titanium dioxide with platinum ions and clusters: Application in photocatalysis. J. Phys. Chem. C 2008, 112, 1124-1131. [CrossRef]

13. Ohtani, B.; Prieto-Mahaney, O.O.; Li, D.; Abe, R. What is degussa (evonik) p25? Crystalline composition analysis, reconstruction from isolated pure particles and photocatalytic activity test. J. Photochem. Photobiol. A Chem. 2010, 216, 179-182. [CrossRef]

14. Alvino, J.F.; Bennett, T.; Kler, R.; Hudson, R.J.; Aupoil, J.; Nann, T.; Golovko, V.B.; Andersson, G.G.; Metha, G.F. Apparatus for the investigation of high-temperature, high-pressure gas-phase heterogeneous catalytic and photo-catalytic materials. Rev. Sci. Instrum. 2017, 88, 054101. [CrossRef] [PubMed]

15. Lappi, S.E.; Smith, B.; Franzen, S. Infrared spectra of $\mathrm{H}_{2}{ }^{16} \mathrm{O}, \mathrm{H}_{2}{ }^{18} \mathrm{O}$ and $\mathrm{D}_{2} \mathrm{O}$ in the liquid phase by single-pass attenuated total internal reflection spectroscopy. Spectrochim. Acta Part A Mol. Biomol. Spectrosc. 2004, 60, 2611-2619. [CrossRef] [PubMed]

16. Slater, J.C. Atomic radii in crystals. J. Chem. Phys. 1964, 41, 3199-3204. [CrossRef] 
17. Chang, T.-Y.; Tanaka, Y.; Ishikawa, R.; Toyoura, K.; Matsunaga, K.; Ikuhara, Y.; Shibata, N. Direct imaging of pt single atoms adsorbed on $\mathrm{TiO}_{2}$ (110) surfaces. Nano Lett. 2014, 14, 134-138. [CrossRef] [PubMed]

18. Xiaogang, L.; Wentuan, B.; Lei, Z.; Shi, T.; Wangsheng, C.; Qun, Z.; Yi, L.; Changzheng, W.; Yi, X. Single-atom pt as co-catalyst for enhanced photocatalytic $\mathrm{H}_{2}$ evolution. Adv. Mater. 2016, 28, 2427-2431. [CrossRef]

19. Hanaor, D.A.H.; Sorrell, C.C. Review of the anatase to rutile phase transformation. J. Mater. Sci. 2011, 46, 855-874. [CrossRef]

20. Kempler, P.A.; Gonzalez, M.A.; Papadantonakis, K.M.; Lewis, N.S. Hydrogen evolution with minimal parasitic light absorption by dense co-p catalyst films on structured p-si photocathodes. ACS Energy Lett. 2018, 3, 612-617. [CrossRef]

21. Hernley, P.A.; Chavez, S.A.; Quinn, J.P.; Linic, S. Engineering the optical and catalytic properties of co-catalyst/semiconductor photocatalysts. ACS Photonics 2017, 4, 979-985. [CrossRef]

(C) 2018 by the authors. Licensee MDPI, Basel, Switzerland. This article is an open access article distributed under the terms and conditions of the Creative Commons Attribution (CC BY) license (http://creativecommons.org/licenses/by/4.0/). 